Administrative Issues Journal: Connecting Education, Practice, and Research, Winter 2020, Vol. 10, No. 2: 46 - 59. DOI: 10.5929/2020.10.2.4

\title{
When Culture and Change Collide In Higher Education: A Case Study at One University
}

\author{
Steven A. Petersen, Ed.D. \\ Truman State University
}

\section{Susan M. Bartel, Ed.D.}

Maryville University

\begin{abstract}
Leaders in higher education regularly find themselves at the intersection of change, torn between their institution's history and culture, the intrinsic value of education, market needs, and the desires of alumni, current, and prospective students. Higher education is often labeled reluctant to change, and many believe any change initiative not aligned with the institution's culture is almost certain to fail. This study provides evidence that leaders in higher education can implement change that is incongruent with organizational culture while maintaining harmony among the institution's ideals and constituents.

University $\mathrm{X}$, a medium-sized, highly regarded public institution located in a rural area, implemented its first fully online degree program, which was widely perceived as being incongruent with the organization's culture. A detailed analysis of eight environmental factors and an adaptation of Kotter's (1996) eight-step change model contributed to the overall success of this change. The keys to implementation were developing an in-depth understanding of the culture while ensuring there was both a need for change and adequate support among stakeholders. Developing a group to champion and sustain the initiative was also critical. The common thread throughout the entire change process was the frequent and effective communication maintained by the organizational leaders. The culture shift initiated by the change also allowed the institution to move quickly to transition to alternative teaching methods during the COVID-19 pandemic of 2020.
\end{abstract}

Keywords: case study, change in higher education, change model, culture, leadership

ackground: Now more than ever, higher education finds itself at a crossroads where traditional views of education's intrinsic value collide with market needs and the desires of key constituents, stakeholders, or customers (Baker \& Baldwin, 2015). Change can be difficult in higher education for several reasons, not the least of which is that any change from the status quo involves inherent risk (Beattie et al., 2013). There is a risk that people will not understand the new way of doing things and will

PETERSEN \& BARTEL / DOI: 10.5929/2020.10.2.4 
either feel or actually become less valuable to the organization. There is a risk that some will lose their "expert" status or prestige if they were critical in building the old way of doing things, and there is the risk that the proposed change will not produce the intended results. Change means going from the known to the unknown, and that involves risk and discomfort (Kotter, 1996). Many would rather be certain of the outcome in their current situation than risk loss or failure by trying something different, even if there is a high probability the change's outcome will produce more favorable results. Nevertheless, if institutions of higher education are to remain relevant in educating the public, they must adapt to their environment and the ever-evolving needs of the market, society, their students, and students' parents.

Organizational leaders frequently find themselves in situations where their changing environment mandates the implementation of new initiatives. Such changes are often seen as necessary to maintain relevance, but may not be viewed as congruent with the organizational culture of the institution. A detailed literature review on the topic suggests that making an organizational change that is incongruent, or perceived as incongruent, with organizational culture is regularly met with resistance and often fails. This study will explore how leaders at one university implemented a change that was viewed by many as incongruent with the university's culture.

University $\mathrm{X}$ is a medium-sized public institution that is consistently ranked quite highly in its category in US News and World Report's America's Best Colleges, and in other college and university ranking systems. It has a stellar reputation for being an affordable institution that delivers a high-quality education. Until very recently, it offered educational programming only in a residential setting. There were no fully online degree programs and relatively few online course offerings. This study explored the strategies used and challenges faced when University $X$, which is traditionally and historically a residential college, implemented the change to offer its first fully online degree program.

University $X$ is located in a remote, rural setting, in a town that has a population of just under 20,000 , according to the welcome signs at the city limits. Nevertheless, it is the largest town in a 60-mile radius. The institution has experienced a steady decline in student population over the last five years, from well over 6,000 full-time graduate and undergraduate students to its current enrollment of under 4,500. The female to male student ratio is roughly $60: 40$, of which more than $96 \%$ are Caucasian. Its incoming freshman class consistently has an average ACT of 27, and it has an average discount rate of roughly $40 \%$.

The faculty at University $X$ largely control the curriculum through a shared governance structure, with Faculty Senate acting as the collective faculty voice. Faculty Senate operates as one body, with several subcommittees that are responsible for all educational programming and curricular matters. Each of the university's approximately 30 departments have a vote in Faculty Senate. A significant change to any curricular matter, such as offering a new program of study, is sent to the governance committee as a bill. If the bill is approved by Faculty Senate, it goes to the university president, who has the authority to sign the bill and recommend it be made into university law, or to veto it. The ultimate decision on any bill being signed into law, however, is the purview of the university's Board of Governors. It can take months for a new academic program to weave its way through the university governance structure, even under circumstances where there is little resistance or objection. If the new program has dissenters, the process can take exponentially longer and may never come to fruition at all.

\section{The Study}

\section{The Problem}


Leaders in higher education are faced with the challenge of implementing changes that continue to make the organization relevant and desirable to current, incoming, and prospective students. Additionally, it is necessary to maintain goodwill and value with internal and external stakeholders, including faculty and staff, alumni, political stakeholders, and the community. Sometimes these multiple and varied perspectives are seemingly at odds. How do leaders in the academy implement a change initiative when some stakeholders do not perceive the desired change as being in alignment with the organizational culture of the institution?

\section{Research Design}

This study is an instrumental case study bounded by location, time, and specific event. An instrumental case study is the study of one particular case to determine or "better understand a theoretical explanation that underpins a particular issue" (Hancock \& Algozzine, 2017, p. 41). The study explores the strategies used and barriers encountered when one mid-sized public institution of higher education implemented a change initiative that was not perceived as being in alignment with the culture of the organization. The purpose of the research is to inform leaders contemplating a change of one institution's process in implementing a change. It will provide insight into the obstacles faced, along with ways to overcome them, and ultimately show how University $X$ implemented a change that was widely viewed as incongruent with its organizational culture. The methods used by the leaders at this particular institution are not transferable to all institutions of higher education, but could provide an example of change implementation strategies for leaders at institutions that share similar structural, organizational, or cultural characteristics.

\section{Methods/Data Collection Tools}

Data was collected and triangulated using three separate methods. An archival search was conducted of all faculty governance meeting minutes and other historical reports that might inform the researcher of institutional factors present at critical times to create the need for, or obstacles to, change; observations were kept in a field notes journal from meetings and conversations with the researcher's peers and colleagues about this change initiative; and finally, the researcher conducted in-person, semistructured interviews with current and former employees involved in this change initiative. This method of using multiple sources in the data collection effort was critical in enhancing the credibility of the study and ensuring the reliability of the data (Privitera \& Ahlgrim-Delzell, 2019). Trustworthiness measures contributing to the reliability of the study included peer review, transcript review, reflexivity, and an audit trail.

\section{Participants}

The researcher initially selected 16 participants to interview for this study. Each of the 16 participants were selected through a process of identifying those who had some part in implementing the change initiative. By the end of the eighth interview the topics and themes being identified had become redundant, and it was clear data saturation had been reached. Upon conclusion of the eighth interview, the representation of participants in the research contained a well dispersed cross section of former and current employees, as well as faculty and administrators.

\section{Literature Review}

The review of the existing literature surrounding culture and change in higher education uncovered numerous theoretical lenses through which to view change, as well as a variety of change models for leaders to emulate while attempting change on their campus. However, leaders contemplating 
a change initiative must first acquire a firm understanding of their institution's organizational culture (Naidoo, 2013). The culture of an organization is its deep-seated personality that is a side effect, or possibly the result, of long-standing traditions, shared values, ideologies, and beliefs of the people who work there and of the organization itself (Peterson \& Spencer, 1991). An organization's culture encompasses the climate and reputation of the organization.

William H. Bergquist's (1992) original theory of institutional archetypes of culture identified four interrelated organizational cultures found in higher education. These are the collegial culture, the managerial culture, the developmental culture, and the negotiating culture. Bergquist defines each culture as indicating where the organization finds its meaning, and what type of behavior and practices it values. Bergquist (1992) asserted that all members of an organization, and organizations themselves, take on one of these cultures more predominately than the others, even though the others are always present. Recognizing the added complexities of the modern world, in 2008 Bergquist added two additional cultures. The virtual culture speaks to the increasing role technology plays in higher education since the turn of the century, and largely in response to the virtual, the tangible culture is that which values its community, physical presence, and the traditional roots of a face-to-face educational setting (Bergquist \& Pawlak, 2008).

William G. Tierney's theory of unique institutional culture contained the six cultural categories of environment, mission, socialization, information, strategy, and leadership (Tierney, 1991, 2006, 2016). Tierney (as cited in Kezar \& Eckel, 2002) suggested that by examining all six of these categories, one can develop a better idea or much clearer picture of an institution's organizational culture.

Kezar and Eckel (2002) concluded that both Tierney's and Bergquist's theories are sufficient to obtain a general idea of an institution's culture, but by combining the two frameworks a more detailed level of understanding can be achieved. Relevant findings in their study were that change should not be attempted, nor a change model even selected, until a thorough understanding of the culture has been attained (Kezar \& Eckel, 2002). An understanding of organizational culture will provide valuable insight as to what, if any, resistance might be met during the change process and what change strategies might have the best probability for success.

Leaders must be familiar with several types of change theories and models so they select only those that are most appropriate for the culture of their particular organization. In organizations as complex as institutions of higher education, using a single model or lens through which to view any situation poses a hazard of leaving out vital details that different perspectives might reveal (Kezar \& Eckel, 2002). Several environmental factors should be studied to inform decisions in each step of any change process regardless of which model or lens one is using to view a situation (Kezar \& Eckel, 2002). A blend of the STEEPLED analysis (Buller, 2015) and Kotter's (2014) accelerate change model provided the theoretical lens through which to view the change studied in this instrumental case study.

In the STEEPLED analysis, leaders or change agents scan the eight different environmental factors that make up this acronym to determine how internal and external influencers might impact the current situation. The eight environmental factors, or drivers of change, are social, technological, economic, ecological, political, legislative, ethical, and demographic (Buller, 2015). This environmental scan focuses on drivers of change that one cannot always control but that have a tremendous impact on the things that can be controlled or affected (Buller, 2015).

Kotter (1996) spelled out eight specific and sequential steps a leader should use to usher an organization through change. His eight steps are to establish a sense of urgency, create a guiding coalition, 
develop a vision and strategy, communicate that change vision, empower broad-based coalition, generate short-term wins, consolidate gains and produce more change, and anchor the new approaches in the culture of the organization (Kotter, 1996). Many felt Kotter's eight-step model lacked validity, and may not translate well into the world of higher education (Appelbaum et al., 2012). Top-down driven initiatives generally face more resistance in higher education and organizations that operate with a shared governance or decentralized organizational structure (Buller, 2015).

Kotter (2014) updated his former model and introduced the idea that an organization is comprised of two different operating systems-the hierarchy and the network. This method produces a more organic, or bottom-up, essence to the change so that people might find it easier to take part in and support the change, in contrast to a top-down, forced change initiative. The main difference between the 1996 model and the 2014 model is in the former, Kotter suggests that a leader or core group of leaders in a hierarchical system drive the change initiative and that they guide, or sometimes even force, the entire organization through the eight sequential steps. The accelerate model suggests that once a leader or someone else identifies an opportunity that will require change, a core group of people from within a networking system should work through the eight steps of the model as a separate entity inside the organization.

An additional difference between the initial eight-step model and the accelerate model is that in the former, Kotter (1996) suggested that not only were the steps sequential, but also that it was critical to complete one step before beginning the next. In the accelerate model, Kotter (2014) asserts that for maximum effectiveness, all steps can operate simultaneously and continuously throughout the change process.

\section{Context for the Case}

\section{Environmental Scan Using the STEEPLED Analysis}

Studying the organizational culture to gain an understanding of how it might impede or assist in a change effort provides the foundation for understanding the case. As both a product of and a contributor to its environment, organizational culture must be studied in the context of its operating environment. Throughout the change process of implementing its first fully online degree program, University X's environmental scan included all elements of the STEEPLED analysis. This level of scrutiny ensured that both the internal and external environments indicated a need for, and a willingness to implement, a change initiative that could potentially clash with many stakeholders' perceptions of the university's culture. All eight environmental factors of the STEEPLED analysis indicated there could be support for such a change, but two areas surfaced several times throughout the case study process: the economic and demographic environments.

University $X$ had been suffering from a mostly flat allotment of state appropriations for over a decade and in the last few years it experienced a steady decrease in full-time enrollment. While costs of learning materials, technology, service contracts, equipment, and other items that allow the institution to provide a high-quality education were increasing, the university's revenue generated was decreasing precipitously. It was clear that University $X$ had to find a way to generate additional revenue if they wanted to maintain what the institution valued and had become well known for in the region-being a highquality public institution that provided an exemplary yet affordable undergraduate education. Every participant interviewed stated this sentiment in some way. One such participant concluded, "Even though there was tremendous need in the nation and region for qualified people with the type of education proposed, which supported the decision to develop an online program, it was clear to everyone involved 
that revenue generation was an important factor in getting this program initiated" (Participant Three, personal communication, October 3, 2019).

It was becoming increasingly difficult and expensive to recruit traditional college students to come to University $X$ due to its rural, remote location. Enrollment numbers at the institution had been declining for several years, in part due to a significant demographic shift in the population. In the region of the country where University $X$ is located, the number of people in the traditional college-age range of 18 to $24 \mathrm{had}$ been decreasing. As the number of available high school graduates decreased, the percentage of people enrolling in residential colleges also declined. The state which houses University $X$ was among the five states that saw the most substantial decrease in the percentage of population enrolling in college for the fall 2019 term.

While conducting the STEEPLED analysis, the president and other leaders of University $X$ recognized this demographic shift and the resulting downward trend in revenues generated. They knew that something different had to be done if the institution was going to continue to thrive in the financially constrained times they were currently experiencing. In the interview process, Participant Four (personal communication, October 10, 2019) said that numerous leaders realized that the enrollment portfolio had to be diversified if the institution was going to survive and continue to be the type of institution it had built its reputation on for the last several decades.

Just like an investment portfolio, an institution's enrollment portfolio must include a number of diverse ways to generate revenue and attract students so that when there are cyclic downward trends that negatively impact enrollment of one demographic-traditional, residential college students, for example-a different population of students can sustain the institution. (Participant Four, personal communication, October 10, 2019)

Numerous participants mentioned that in their opinion University $X$ could no longer survive by catering solely to traditional-age college students who were getting their education in a residential setting.

The environmental scan of the institution showed a change was needed to diversify the university's enrollment portfolio. The leaders selected a plan to develop a fully online degree program. Offering online educational opportunities could increase and diversify the enrollment portfolio by attracting students from around the world, and it would not require students to physically relocate to University $\mathrm{X}^{\prime}$ 's remote location to take classes.

\section{Results}

Through the interview and archival search processes of studying elements that allowed University $X$ to successfully implement a change that seemed incongruent with its organizational culture, several themes emerged. The most common themes included studying organizational culture to gain an understanding of how it might impede or assist in the effort and how to combat the obstacles it might emplace, having a defined leader or a group of people who championed the effort from conception to completion, providing evidence of a need for the change, gaining support across a wide array of stakeholders for the change, and maintaining effective communication while having the perseverance and determination to see the initiative succeed.

\section{Understanding the Culture}

The decentralized organizational structure of institutions of higher education means that new initiatives are most likely to succeed if they are developed from the ground up, rather than being directed from the top down. Leaders must fully understand the culture, and in the case of University $\mathrm{X}$, leaders 
must understand that the administration cannot just declare something and expect it to happen (Participant Eight, personal communication, October 30, 2019). One participant stressed that, "University $X$ is a very traditional residential college, and the culture of innovation has just not been present. Change takes a very long time here, and is nearly impossible if the faculty are not on board" (Participant One, personal communication, September 27, 2019). The culture of commitment to shared governance and the authority of the faculty governing body concerning all curricular matters made it clear the best method to create change of this kind was to gain buy in from faculty and mid-level administrators. The university formed a committee to develop the concept of offering a fully online program, and according to Participant Two (personal communication, September 30, 2019), it was at this point that positional leaders at the top levels of the institution handed the initiative off to a group of people who were henceforth considered the champions of the effort.

\section{Identifying a Champion}

Multiple participants commented it was their impression that it was the president or positional leader of the institution who originally came up with the idea to create a fully online degree program. In fact, the idea for the program was a result of a lengthy and arduous scan of the institution's environment. Leaders must continuously scan the environment in which they operate to maintain awareness of potential threats and opportunities. One's operational environment contains both internal and external factors that can influence or impact an organization's ability to accomplish its mission and goals. Leaders must understand when their environment has changed, is changing, or is about to change (Mattis \& West, 2019). Through the process of scanning the environment, strategic leaders are positioned to identify opportunities for change, but that is not to say that they are or should be the champion of the change effort. Especially in organizations with decentralized structures, it is often better to have someone other than the positional leader to be the change agent.

Finding a person or group of people to champion the change initiative is crucial because it shows the organization that the initiative is not simply an administrator-driven idea, but is one that has a range people who support it and believe it can be successful. Thus, the initiative will be sustained through the work of others who share the vision. Participant Seven stated finding the right champion is essential: "Someone passionate about the change will work to see it through regardless of how many obstacles are put in front of them or who gets mad about it, is critical to success" (Participant Seven, personal communication, October 23, 2019). "If you can't find the right person or people to champion the effort, you might be attempting the wrong change" (Participant Three, personal communication, October 3 , 2019).

The right people were found, and the champions of this effort were charged with determining what program should be selected as the first fully online program at University $X$, as well as figuring out how to make the first fully online program work at the institution and see it through to completion. The "how" included things like developing the curriculum and working with information technology services to set term start and end dates for online courses inconsistent with the in-person courses, so that online courses could have multiple start dates throughout the academic year (Participant Seven, personal communication, October 23, 2019). However, a large part of this committee's work was going to be focused on persistence and seeing the project through any obstacles it faced, once the "how" was known.

To ensure the project didn't stall out, the committee identified the need to gain widespread support for what was going to be a change many might consider inconsistent with the institution's organizational culture. The stakeholder groups the committee focused on were students, alumni, the community, and the faculty. According to Participant Seven (personal communication, October 23, 2019), 
the group of champions knew that the more support the initiative had from all stakeholders of the institution, the better chance it had to meet the least amount of resistance at Faculty Senate, and ultimately pass through the governing body. However, to gain the support of the stakeholders, a program had to be identified and the need for the change would have to be understood by all.

\section{Establishing the Need for Change}

The STEEPLED analysis provided evidence of a need for the institution to make a change, but in order to gain support for the change, the group of champions had to determine which type of program would best suit the needs of all stakeholders and would have a high probability of succeeding for both the university and the students in the program selected. The champions studied the labor market needs in the nation and the state, and specifically in the region and its local community. One need that kept surfacing was the demand for qualified mental health and K-12 school counselors. This particular workplace shortage in the region meshed nicely with the types of programming University X could offer, given the faculty and departments on campus that were more in support of offering online programming (Participant Six, personal communication, October 17, 2019). Coincidentally, University X had a dormant counseling program. Selecting this as its first fully online degree program would allow efficient use of existing curriculum. These were factors that largely influenced the decision to select the dormant program for this initiative (Participant Six, personal communication, October 17, 2019).

Furthermore, Participant Six (personal communication, October 17, 2019) stated the initial support of some faculty and staff who were passionate about the counseling curriculum being offered again also helped the leaders at University $X$ decide to choose counseling as its initial fully online degree program. The leaders and committee knew that garnering enough support for the change would be the key to implementation and having faculty members who were determined to revive one of their programs would be a benefit. However, the leaders and committee also knew that a small number of faculty members might not be sufficient support to make a programmatic change so contrary to the organizational culture. Widespread support would be needed from numerous university constituents, and once the need for a change was established and program was selected, the committee began working to obtain that support (Participant Eight, personal communication, October 30, 2019).

\section{Garnering Broad-Based Support}

The participants of the study felt very strongly that University $X$ had an ethical obligation to ensure the program selected be one that would provide graduates a high-quality education so they would be marketable in their discipline upon graduating from the program. Participant Five (personal communication, October 16,2019 ) admitted that initially they might have been more of a hindrance to the effort than a supporter because they were concerned the online modality would lessen the quality of the curriculum. Participant Three stated, "From an ethical standpoint, it was also important the program be of high quality, and not just something to generate revenue by taking students' money and not caring if they succeed in the program or life after graduation" (Participant Three, personal communication, October 3, 2019). All participants shared the sentiment that they could not get on board with the decision until the program met their qualifications for quality and ethical standards. "Through conducting my own research, I discovered there were a few other very reputable institutions across the nation delivering a counseling program through the online modality" (Participant Five, personal communication, October 16, 2019). Knowing that other institutions were offering high-quality online counseling programs satisfied the 
ethical requirement for supporting the decision. Subsequently, internal interest in and support for the program grew.

Participant Two (personal communication, September 30, 2019) mentioned that they believed reaching out to counselors and other educators who had already graduated from the institution would yield much of the support the institution needed from alumni stakeholders, as well as provide a recruiting pipeline for students once the program was up and running. The committee also began discussions with local and regional school districts to validate the need and garner support for such a program. University $X$ has a sizeable number of psychology and education students, so an effort was undertaken to gauge and gain support from this group of stakeholders to both determine the level of interest in a master's program in counseling and begin recruiting the inaugural class. Through the process of garnering support, it became clear that a master's degree in mental health and school counseling was the best programmatic candidate for University $X$ to roll out as its initial fully online degree program (Participant Two, personal communication, September 30, 2019).

There appeared to be sufficient support from stakeholders, and there was a bonus to having University X's first fully online degree program be a master's degree. This allowed the change agents to attempt the initiative outside of what Kotter (2014) defined as the hierarchy operating system of the institution, and instead to attempt it within its network operating system. University $X^{\prime}$ 's mission is primarily to provide a quality undergraduate education that is grounded in the liberal arts. It does offer some professional and pre-professional programs and has the masters Carnegie classification. However, the organizational culture, according to Participant Seven (personal communication, October 23, 2019), has placed laser focus on the residential, undergraduate college experience. It has remained quite indifferent at best, or even opposed, to online programmatic offerings. "The organizational culture was one that would make online program offerings quite challenging" (Participant Seven, personal communication, October 23, 2019).

Over $50 \%$ of the nearly 300 faculty members at University $X$ were tenured, and most of those were full professors who had been at the institution for decades. Of these, many believed that the quality of online instruction would never compare to what they could offer in an in-person class, and that online programmatic offerings would ultimately devalue the University $X$ experience and damage its reputation. Offering the first fully online degree program as a master's degree allowed the faculty of this mindset to continue operating in the status quo of the institution-the hierarchy operating system. The change, on the surface, was taking place behind the scenes in the network operating system and did not directly affect or impact what those faculty members were doing. "Because of this, the level of resistance to the new program was actually much less than what the leaders of the institution anticipated" (Participant Six, personal communication, October 17, 2019).

Once the curriculum was developed and the program was finally ready to move to faculty governance for a vote of approval, it passed unanimously. According to Participant Four (personal communication, October 10, 2019), that moment was a turning point for University X. It was the beginning of a change in organizational culture and how the institution viewed online offerings. "Once the online degree program was approved as an acceptable practice, faculty-especially newer, younger facultybegan expressing more interest in teaching online" (Participant Four, personal communication, October 10, 2019). University leaders and faculty began discussing ways to expand online programmatic opportunities and even begin offering undergraduate opportunities in the online arena. Online opportunities started becoming part of everyday conversation and communication when talking about new initiatives. Online education began to slowly become part of who the organization is and how it 
operates on a daily basis. It was becoming part of the organizational culture, where just two years before, it was distinctly absent from the culture (Participant Seven, personal communication, October 23, 2019).

This adjustment in culture regarding online education had the added benefit of making University X's transition to alternative teaching methods during the COVID-19 pandemic of 2020 much less painful than it may have otherwise been. It is not that the leaders or change agents took on this initiative with the belief that there might soon be the need for an institutional response to a worldwide pandemic, but having the foresight that enrollment portfolio diversification was needed facilitated a better preparedness when that situation arose.

\section{Determination, Perseverance, and Communication}

The most common theme that surfaced in the research process and was supported by document review, field notes, and interviews was the leadership's determination to see the change succeed and to maintain frequent, effective communication at all levels throughout the entire process. Participant Eight (personal communication, October 30,2019) asserted that the change had to succeed because it was just too long since University $X$ did anything bold and new. However, there were some faculty who were not in favor of the change from the onset. These people were identified as potential obstacles, and there was an intentional effort to educate and inform them about why the change was necessary, what the value to the institution and its constituents were, and how they could either accept and embrace the change or simply stay out of the way and watch it happen around them. One participant said if people were still nonsupportive after those efforts, they were simply disregarded for the remainder of the process, explaining that,

The research indicated strong support among a wide array of stakeholders, so we did not need to convince everyone on campus that it was the right thing to do. At that point, we just had to make sure they didn't have too many opportunities to get in the way. (Participant Eight, personal communication, October 30, 2019)

Many of those who were initially unsupportive did choose to embrace the change. However, many opted for continuing to operate in the institutional status quo, believing the change was not going to impact them. Bypassing the non-supporters prevented them from becoming obstacles to the initiative.

Frequent and effective communication was critical during the change process from the beginning to the end, and even well after the change occurred. At all phases, but especially in the beginning, establishing and widely communicating the need for the change was valuable, as indicated by Participant Four (personal communication, October 10, 2019). The institutional leaders spent months speaking about how appropriations and enrollments were declining, and the institution's need to find new ways to make University X's high-quality education more accessible to an even more diverse population. This message was sent to students, faculty, and staff every time an opportunity arose. There were also several opportunities for all constituents to weigh in on how they felt about offering fully online programs. Participant Eight (personal communication, October 30, 2019) was certain this method of information gathering was key in informing leaders of how they needed to shape their messages with certain stakeholders to provide optimal results.

The institutional leaders continued to update the campus community and the stakeholders on how the initiative was progressing, and celebrated small victories along the way to show the campus that the change was happening. Creating and securing short-term wins is step six and an integral part of Kotter's (1996) change model. Participant Four (personal communication, October 10, 2019) said highlighting victories as they occurred was deliberate and was crucial to maintaining momentum for the 
change. Some of these small victories were when the curriculum was ultimately developed, when the director of the new program was hired, and when student interest in the new program became sufficient to provide evidence it was going to succeed. "There were even occasional press releases and social media updates on how the new program was developing to keep the local community and alumni informed" (Participant Four, personal communication, October 10, 2019).

Once the change was made, in this case when the bill passed through faculty governance, there was still much communication needed to ensure the change was successful and yielded the results the institution had hoped for. The people who worked on the change initiative needed to be publicly congratulated. According to Participant Two (personal communication, September 30, 2019), this served a couple of purposes. First, it showed the institution's appreciation for the work they did, but equally important is that public recognition showed everyone else that the change had been made and the task was complete. Seeing that change is possible can inspire others to think of initiatives that could be attempted in order to better themselves and the organization. It may, and in this case, did, inspire some people who were initially on the fence about the change to embrace it, learn new things, and help the organization improve access to its quality educational experience (Participant Six, personal communication, October 17, 2019). Successful change, when communicated widely and publicized effectively, is an accelerator for more successful change. As each new person in an organization embraces a change, the mindset and culture of the organization begin to change (Kotter, 2014).

\section{Discussion}

Change in higher education is hard, or at least it can be. Due to the decentralized organizational structure, shared governance, and a number of other factors that make higher education a unique place to live and work, it is commonplace to think it is nearly impossible for leaders to effectively implement significant change that is incongruent with the institution's organizational culture. This study provides evidence to the contrary. Leaders can successfully implement change-even change that is incongruent with organizational culture-if they first develop an in-depth understanding of the culture, spend some time researching their environment, and show strong evidence of a need for the change (Buller, 2015; Kotter, 1996). However, even a proven necessity will not motivate everyone to embrace change that is incongruent with long-standing tradition and organizational culture.

For this reason, leaders need to amass broad-based support for their initiatives and enlist champions who believe in the effort and are willing to see the change through (Kotter, 1996). Allowing the change to take place inside the organization under a network operating system while the organization as a whole continues to operate under the status quo is the method that University $X$ used to implement the change studied (Kotter, 2014). Once an effective change is made inside the organization, people will see its impact and want to become a part of it. Slowly, more people will embrace the change. Over time, what was once viewed as a change or new becomes a normal part of the organization and its daily operations. The change simply gets incorporated into the organizational culture and becomes the new normal (Kotter, 1996).

This particular change, from the idea's conception to the approval of offering a fully online degree program, took place over a period of 18 months. The initiative was the beginning of a change in culture at University $X$, and though organizational culture is in a constant state of change due to an organization's ever-evolving environment and the people within, a visible and distinctive change in culture is generally not realized for a long time. Likely, it will be many years before University $X$ fully recognizes that providing high-quality online education has become a subconscious part of its organizational culture. Still, this single initiative could very well be viewed as the catalyst for that culture change. 
Coincidentally, the change initiative was implemented about a year prior to the 2020 outbreak of the COVID-19 pandemic in the United States. This pandemic completely changed the way many institutions of higher education operate and deliver their curriculum. When the pandemic hit, the culture shift of moving to new modalities to diversify its enrollment portfolio had already begun at University $\mathrm{X}$. Many faculty and departments were already exploring how to adapt to delivering more online educational opportunities when the pandemic made doing that a necessity. This initial change initiative of offering its first fully online degree program opened the door for other online offerings and made it easier for many faculty who had not already been contemplating alternative curriculum delivery methods to visualize how they could quickly turn their existing courses into online courses. Had this culture shift not been already initiated by the change, the institution's ability to quickly respond to the pandemic by moving to teaching solely in the online modality would have been severely degraded. The leaders' consistent environmental scanning of all elements of the STEEPLED analysis, and their foresight to identify the need to diversify the institution's enrollment portfolio set University $\mathrm{X}$ up for optimal success in making the quick transition to alternative instructional methods.

\section{Conclusion/Implications for Practice}

It is important to remember that this example of how leaders at one institution implemented change is not a one-size-fits-all solution to change in all aspects of higher education. Generalized strategies for implementing change can be as harmful as they can be helpful for leaders attempting change (Kezar \& Eckel, 2002). Change models can be extremely valuable lenses through which a leader in higher education can view a change initiative. However, no single change model is applicable to all situations. Leaders have to fully understand the organizational culture, be knowledgeable about numerous types of change strategies, and be flexible enough to adapt to things that will work for their institution at a specific point in time in order to implement change successfully.

In addition to studying generalized change strategies, leaders would do well to study contextbased data to discern which types of strategies might be most effective under the circumstances at their particular institution. Conducting a thorough scan of one's environment and studying the context-based data specific to one's organization prior to attempting change will tune leaders in to the organizational culture and give them a better idea of what types of adaptations to change strategies might yield the best results. 


\section{References}

Appelbaum, S., Habashy, S., Malo, J., \& Shafiq, H. (2012). Back to the future: Revisiting Kotter's 1996 change model. Journal of Management Development, 31(8), 764-782.

Baker, V. L., \& Baldwin, R. G. (2015). A case study of liberal arts colleges in the 21st century: Understanding organizational change and evolution in higher education. Innovative Higher Education, 40(3), 247-261.

Beattie, J., Thornton, B., Laden, R., \& Brackett, D. (2013). 21st-century challenges in higher education: Strategic changes and unintended consequences. International Journal of Educational Leadership Preparation, 8(1), 62-71.

Bergquist, W. H. (1992). The four cultures of the academy. Jossey-Bass.

Bergquist, W. H., \& Pawlak, K. (2008). Engaging the six cultures of the academy: Revised and expanded edition of the four cultures of the academy. Jossey-Bass.

Buller, J. L. (2015). Change leadership in higher education: A practical guide to academic transformation. Jossey-Bass.

Hancock, D. R., \& Algozzine, B. (2017). Doing case study research (3rd ed.). Teachers College Press.

Kezar, A., \& Eckel, P. D. (2002). The effect of institutional culture on change strategies in higher education: Universal principles or culturally responsive concepts? Journal of Higher Education, 73(4), 435-460. http://muse.jhu.edu/article/14868/pdf

Kotter, J. P. (1996). Leading change. Harvard Business Review Press.

Kotter, J. P. (2014). XLR8: Accelerate. Harvard Business Review Press.

Mattis, J. N., \& West, F. J. (2019). Call sign chaos: Learning to lead. Random House.

Naidoo, D. (2013). Reconciling organizational culture and external quality assurance in higher education. Higher Education Management and Policy, 24(2), 85-98.

Peterson, M., \& Spencer, M. (1991). Understanding academic culture and climate. In M. Peterson (Ed.), ASHE reader on organization and governance (pp. 140-155). Simon \& Schuster.

Privitera, G. J., \& Ahlgrim-Delzell, L. (2019). Research methods for education. Sage Publications.

Tierney, W. G. (1991). Culture and ideology in higher education: Advancing a critical agenda. Praeger.

Tierney, W. G. (2006). The changing nature of organizational leadership and culture in academic work. Journal of Research on Leadership Education, 1(1), 1-3. https://files.eric.ed.gov/fulltext/EJ958773.pdf

Tierney, W. G. (2016). The impact of culture on organizational decision-making: Theory and practice in higher education. Stylus Publishing. 


\section{About the Author}

Dr. Steven A. Petersen (spetersen@truman.edu) is a retired Lieutenant Colonel in the US Army, and currently works in academic affairs at a public university in the Midwest. His higher education experience includes positions in administration and as a faculty member. His research interests include organizational behavior, leadership, culture, and change.

Dr. Susan M. Bartel (sbartel@maryville.edu) is a tenured associate professor who teaches in a doctoral program in higher education leadership. Her experience includes positions in administration, faculty, and consulting. Her research interests include gender leadership, change and innovation, and grief leadership. She has received multiple awards for teaching, professional accomplishment, and community service. 